\title{
The Development of Management Units for Site-Specific Farming
}

\author{
B. L. McCann, D.J. Pennock, and C. van Kessel \\ Department of Soil Science, University of Saskatchewan.
}

\begin{abstract}
Image analysis is a valuable tool that can be used to delineate management units for SiteSpecific farming applications. Soil landscapes are often highly variable in terms of their productive potential. Because of the complex nature of these landscapes, only large-scale maps can provide the level of detail necessary for Site-Specific farming. Image analysis of black and white aerial photographs can be used as a cost effective method to delineate soil management units. In this study, extensive field sampling and laboratory analysis were used to characterize a soil landscape belonging to the Oxbow Association. The site was stratified into four management units by grouping the digital numbers on the scanned black and white aerial photograph into categories that reflect the changes in different soil properties across the landscape. The close relationship between the management units and the soil properties suggests that this technique is an effective method for stratifying landscapes into management units.
\end{abstract}

\section{Introduction}

Producers are looking to site-specific farming to increase the efficiency of their operations. It has been long recognized that the productivity on hilly terrain varies greatly from the knolls to the depressions. This variation in productivity reflects the different moisture and soil conditions that exist at the two locations. For example, the knolls tend to be dry and have soils with relatively low fertility levels. In contrast, the low areas generally have more favorable moisture conditions and higher fertility levels. The goal of site-specific farming is to delineate management units -areas with similar productive potential - and apply the right amount of inputs to obtain the best returns.

The stratification of soil landscapes into management units is one the major challenges facing both researchers and producers who are interested in site-specific farming. Over the years, a number of methods have been developed to stratify research sites into units with similar productive potential: (1) detailed soil survey, (2) extensive sampling program, and (3) collection of topographic data. These techniques have been effectively used for research applications but it is not economically feasible to use them for site-specific farming at the farm scale. One of the objectives of this study, is to determine if image analysis of black and white aerial photographs can be used to stratify soil landscapes into management units. If successful, this technique would provide farm managers and agricultural consultants with an inexpensive method for mapping fields into management units for site-specific farming applications. 


\section{Materials and Methods}

\section{Studv Site Description}

The study site is located $40 \mathrm{~km}$ north of Saskatoon, near the community of Hepburn (SW 7-40-5-W3). The site is situated on a glacial till landscape that is part of the Oxbow soil association (Acton and Ellis, 1978). Slope gradients at the site range from 5 to 10\%. Surface drainage at the site is local with the depressional areas separated by linear ridges. These ridges dissect the site at different angles resulting in a hummocky surface pattern. The parent material is a glacial till with a texture ranging from loam to clay loam.

\section{Site Design}

The research site covers an area that is 250 meters by 300 meters. The site encompasses several cycles within this knoll and depression landscape - one cycle extends from one knoll down into a depression and then to the top of the next knoll. A 9 by 11 point grid with a 25 meter sampling interval was used as a guide for the sample collection.

\section{Surveying and Sample Collection}

Once the grid positions were established within the landscape, the grids surveyed and sampled. A theodolite and a measuring wheel were used to establish the points within the grids. A Total Station was used to gather topographic and positional information for both the sampling points and the topographic inflection points within and around the grid periphery. At each grid point, soil cores were extracted and extruded using a truck mounted coring apparatus. Once extruded, the soil cores were described using the Canadian System of Soil Classification (Agriculture Canada, 1978). Samples were collected at $15 \mathrm{~cm}$ intervals to a depth of $60 \mathrm{~cm}$. Finally, in an effort to assess insitu soil salinity, EM 38 reading were taken at each site.

Before any of the soil data can used for image analysis, the sampling points must be georeferenced to the surrounding area with the use a coordinate system. In this study, Global Positioning System Units (GPS) were used to establish the UTM coordinates for the comers of the sampling grids. In order to obtain an accuracy within 1 meter, Differential GPS measurements were taken using 2 Garmin II GPS units. One unit acted as a base station and was set up on an obstruction-free site near the comer of the section. The second instrument was used as a field unit and was deployed to gather positional information for the grid comers and road intersections in the surrounding area. The two instruments gathered positional data simultaneously and stored it within the units. The data were subsequently downloaded into a DOS-based computer where the UTM coordinates were established for each point through post processing.

\section{Laboratory Methods}

The soil samples collected in the field were subjected to a series of analytical procedures that provided information needed to characterize the soils. A number of chemical properties were examined: inorganic carbon, organic carbon, nitrate nitrogen, $\mathrm{p}-\mathrm{H}$, and electrical conductivity. 
Physical components include particle size distribution, moisture content, and moisture retention. Standard analytical techniques were used to gather all the information. The data generated from these procedures facilitated the classification and delineation of management units within the study areas.

\section{Data Processing}

The topographical data was used as the basis for the creation of the digital elevation model @EM). The first step in this process utilized a Fortran program developed by Pennock et al. 1987 which is designed to convert the survey data to $\mathrm{X}, \mathrm{Y}$ and $\mathrm{Z}$ values. The topographic mapping program Rockware was then used to create the DEM for the site. In order to create three dimensional depiction of the site, the graphics program 3D was employed. This program was also used to for the draping the classified image over the DEM (Appendix A, figure 4). The statistical software SPSS was used to in the creation of the box and whisker diagrams. Image Analvsis

The image analysis techniques that were used in this study consists of 5 basic components: (1) image capture, (2) georeferencing, (3) enhancement, (4) analysis, and (5) classification. The first step in this process is image capture or the conversion of an aerial photograph to a digital image. The photograph for this site was obtained from Central Survey and Mapping Agency in Regina, Saskatchewan, Canada and was photographed at a scale of approximately 1:30,000. The photo was then scanned at a resolution of approximately 600 dots per inch with the use of a AGFA Arcus Scanning Device. The area of interest on each photo was delineated and saved as a digital image. Digital images are composed of a two dimensional array of pixels or grid cells. For black and white digital images, the grey tone of each pixel is expressed as a digital number ranging from 0 to 255 with 0 representing black and 255 white.

Before a digital image can be utilized in the image analysis process, the inherent distortion must be corrected through image rectification (ERDAS, 1991). This process involves the projecting of the data onto a plane, and making it conform to a map projection system. The technique utilizes ground control points that act as reference points from which the image points are corrected and assigned UTM coordinates.

Image enhancement is the process in which spatial and spectral enhancement techniques are used to make an image more interpretable for a particular application (ERDAS, 1991). In this study, two enhancement procedures were used on the image to improve its quality: (1) low pass filtering, and (2) histogram stretching. A low pass filter was used to remove much of the random noise on the image caused by cultivation patterns and uneven straw distribution. Histogram stretching was used to increase the contrast of the image in an effort to facilitate classification.

Once the enhancement process was completed, the digital number for each sample point in the grid had to be established, analyzed, and grouped into categories. The sample grid was 
digitized and superimposed onto the enhanced image. The digital numbers for the sample sites were then recorded. Using the soil profile descriptions as a guide, a supervised classification was conducted on the digital image to stratify the landscape into four units based on its spectral characteristics. The spectral characteristics of these units were then compared to various soil properties using box and whisker diagrams. The examination of these relationships facilitated the adjustment of the categories to better reflect the pedological and hydrological conditions at the site. Once the categories had been finalized, colours were assigned to the different categories resulting in a GIS map of the management units for the study area.

\section{Results and Discussion}

The grey tone pattern on black and white aerial photographs is often a reflection of soil properties that may be linked to productivity. The spectral properties of bare soil surfaces are largely governed by soil organic carbon, inorganic carbon, and moisture (Schmidt, 1993). These properties can be either directly or indirectly linked to productivity. Because of these relationships, this study examined the possibility of stratifying soil landscapes into management units according to their spectral properties. Using the soil profile descriptions as a guide, the digital image for the research site was classified into four categories: (1) knolls, (2) mid slopes, (3) lower slopes, and (4) depressions (Appendix A, figure 1). These categories formed the basis for the management units at this site.

The four management units were compared with various soil properties to evaluate their differences in terms of productive potential. Because organic carbon is an indicator of soil fertility, the organic carbon levels were grouped according to the different management units (Appendix A, figure 2). In this box and whisker diagram, there is a clear trend in the organic carbon levels. For example, the knolls have the lowest levels outside of the depressions. These low levels are a reflection of the relatively dry growing conditions and the removal of soil as a result of erosion and cultivation. In both management units down slope from the knolls, the organic carbon levels are much higher than those in the knoll unit. Why the increase in organic carbon? These increases in organic carbon are a reflection of the relatively moist conditions that has favoured abundant plant growth and the subsequent accumulation of carbon. Still further down slope, in the depressional areas, periodic flooding has increased moisture levels to the point where carbon accumulation has been retarded and hence, organic carbon levels similar to those on the knolls.

Soil nitrate levels have a similar relationship to the management units as the organic carbon (Appendix A, figure 3). Like the relative values for organic carbon, the knolls have the lowest nitrate levels for any of the management units. These low values are likely a reflection of the low nitrogen mineralizing potential at these sites. In the two management units just down slope from the knolls, the nitrate levels are higher (Appendix A, figure 3). These higher levels are 
largely a reflection of the relatively high nitrogen mineralizing potential at these sites. This higher potential is primarily a function of the relatively high organic carbon levels. Moving still further down slope, the nitrate levels drop off in the depressional areas. Periodic flooding has created the anaerobic conditions

that enhance loses of nitrogen through leaching and denitrification. These loses, combined with the lower nitrogen mineralizing potential at these sites, result in relatively low nitrate levels.

In order to assess the relationship between the management units and the topography at the site, the GIS map was draped over the DEM (Appendix A, figure 4). Upon examining the diagram, it is evident that there is a good relationship between slope position and management

units. For example, the knoll unit has delineated the areas associated with the upper most sections of the major ridges. These units are generally surrounded by mid-slope units which closely conform to the landscape curvature on the DEM. The lowest points in the landscape are classified as depressions. These units are always surrounded by the lower-slope units. Figure 4 illustrates that there is a close relationship between the topography at the site and the management units that were derived from the black and white aerial photograph.

\section{Conclusion}

Image analysis of scanned panchromatic aerial photographs is an effective and inexpensive tool for delineating soil management units for site-specific farming. The level of accuracy and detail obtained with this method could otherwise be only achieved through a very detailed soil survey at considerable expense. Image analysis is not, however, a panacea. In order for the technique to be effective, the study area must be characterized with the use of existing soil survey information and ground truthing data. The 1:100,000 scale soil survey information acts as a general guide for the broad characterization of soil landscapes. Ground-truth data, when collected in conjunction with a GPS, provides the information needed to locate and establish the spectral properties of specific soil management units within the soil landscape. Ground-truth data would not, however, need to be collected for all study sites with the same map unit. Once the spectral properties of a representative site were characterized, the information could easily be extrapolated to other sites with the same map unit. Utilizing image analysis in this manner should allow researchers and producers involved in site-specific farming to stratify their soil landscapes into management units that reflect the differences in the productive potential within the field 


\section{Reference List}

Acton, D.F. and J.G. Ellis (1978) The Soils of the Saskatoon Map Area. Saskatchewan Institute of Pedology. Publication S4. University of Saskatchewan, Saskatoon, Saskatchewan. Agriculture Canada Expert Committee on Soil Survey (1978). The Canadian Svstem of Soil Classification. 2nd Edition. Agriculture Canada Publication 1646. ERDAS, Inc. (1991). Field Guide. ERDAS, Inc., Atlanta, Georgia..

Pennock, D. J., B. J. Zebarth and E. de Jong (1987). Landform Classification and Soil Distribution in Hummocky Terrain, Saskatchewan, Canada. Geoderma. 40: 297-3 15. Schmidt, T. K. (1993). M.Sc. Thesis. University of Saskatchewan, Saskatchewan, Canada. 


\section{Appendix A}

\section{0 meters}

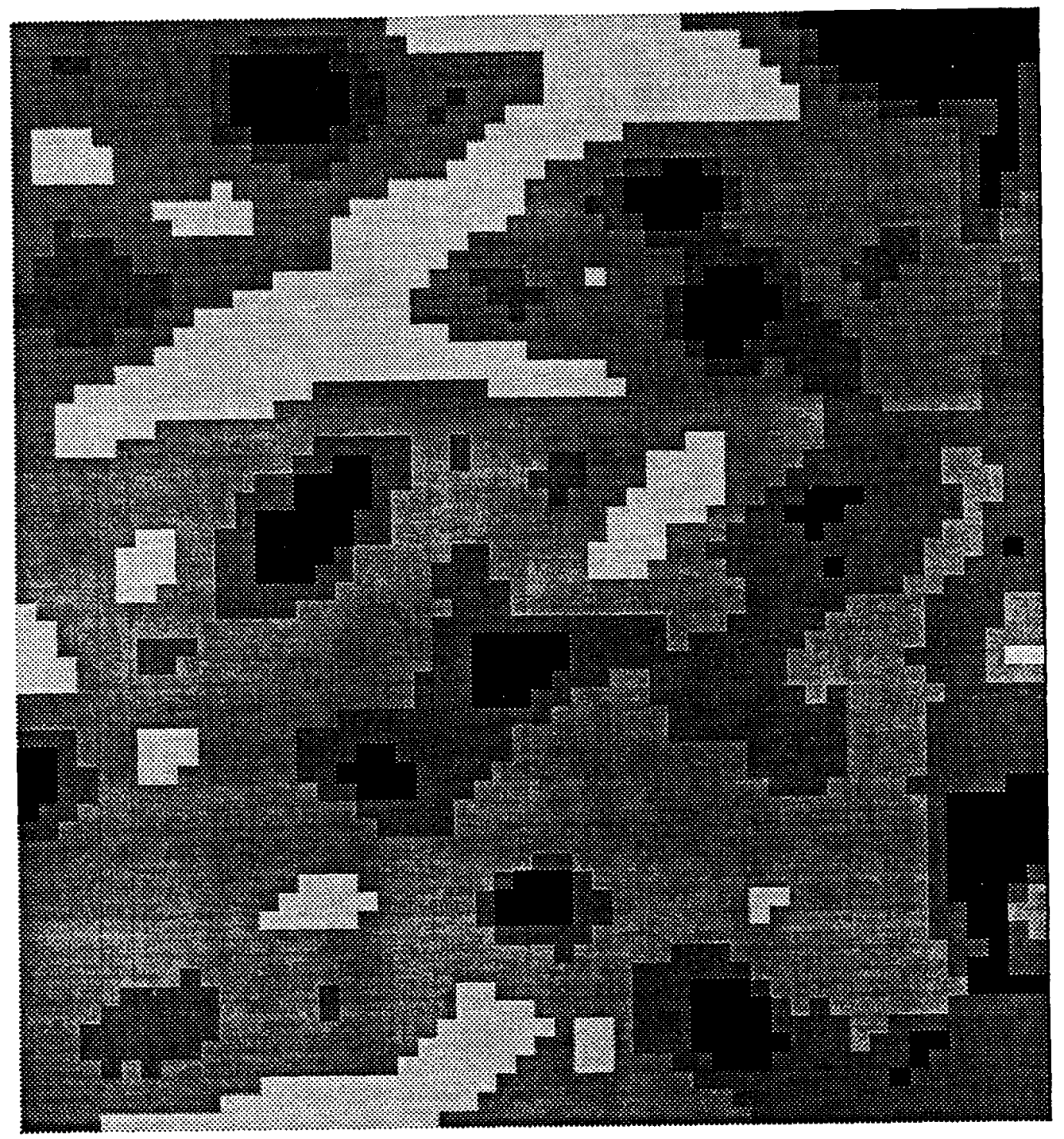

(Figure 1) Soil Management Units Derived from Digital Image.

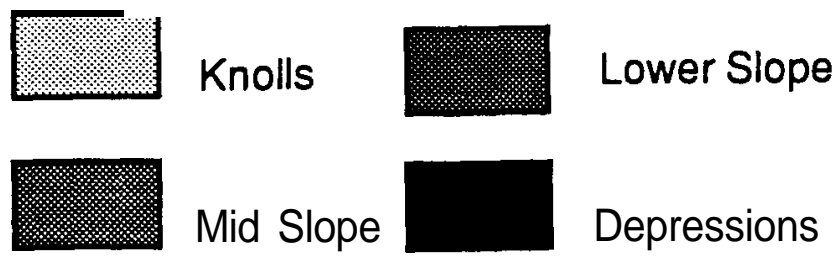




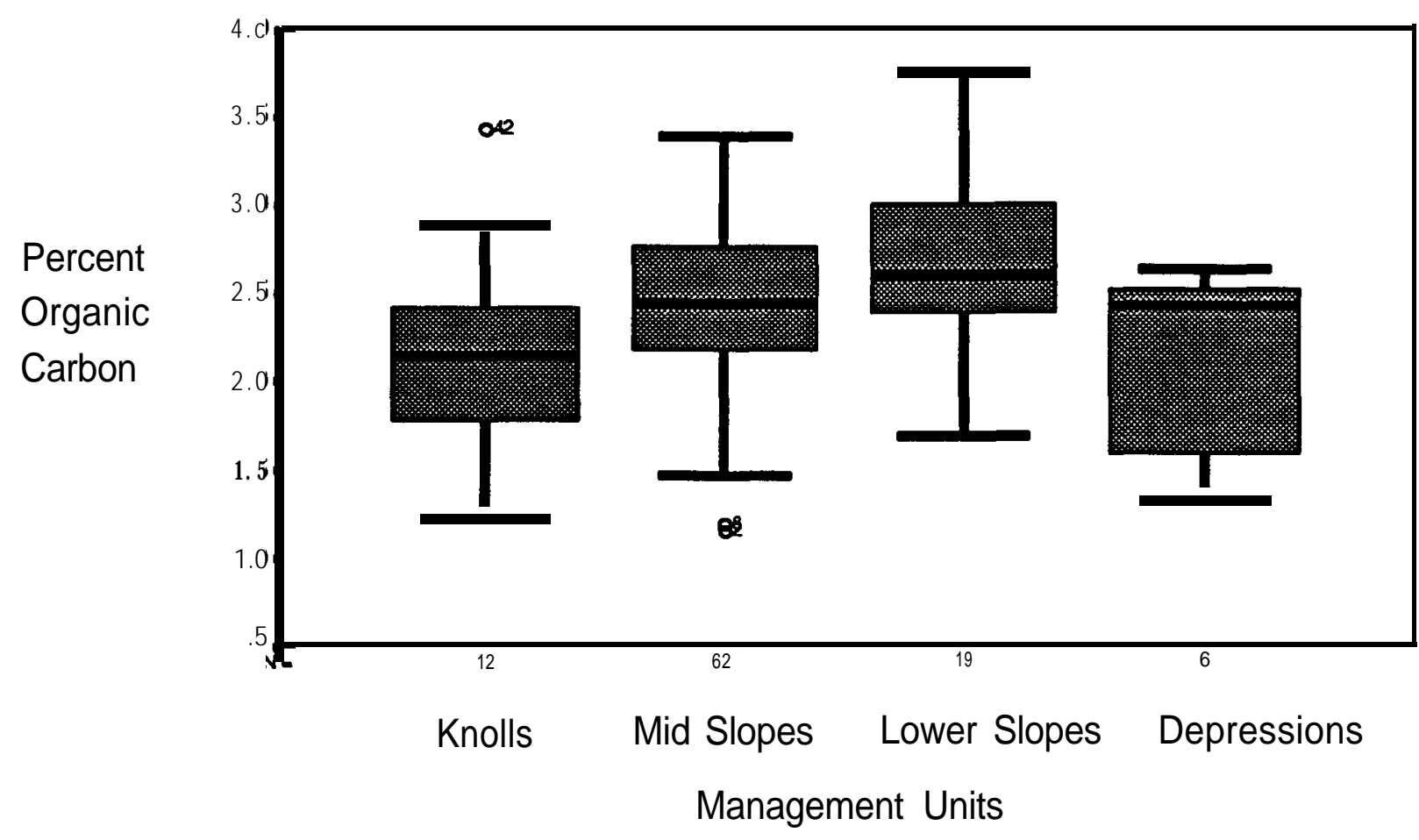

(Figure 2) Soil Organic Carbon and Management Units

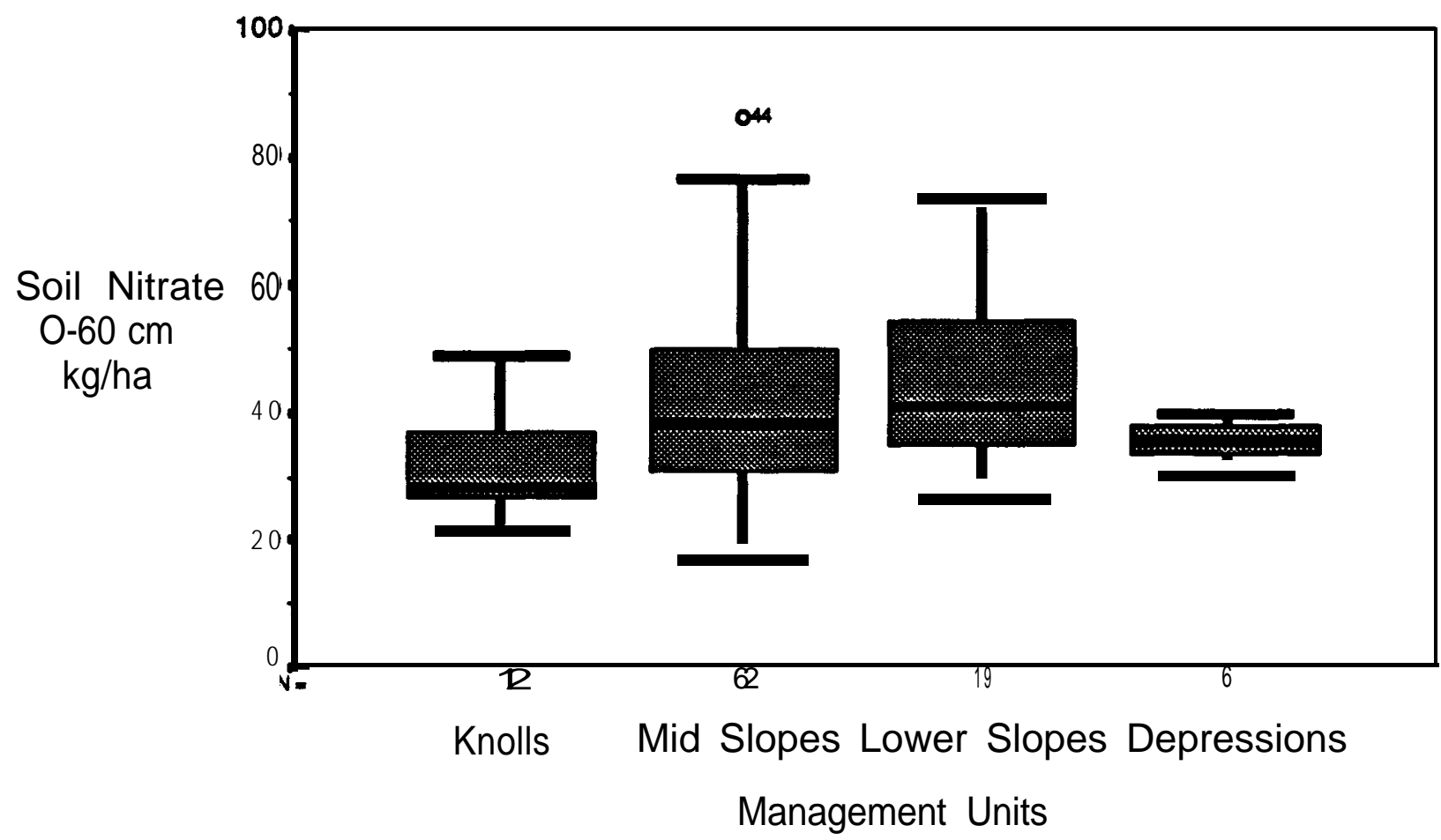

(Figure 3) Soil Nitrate and Management Units 


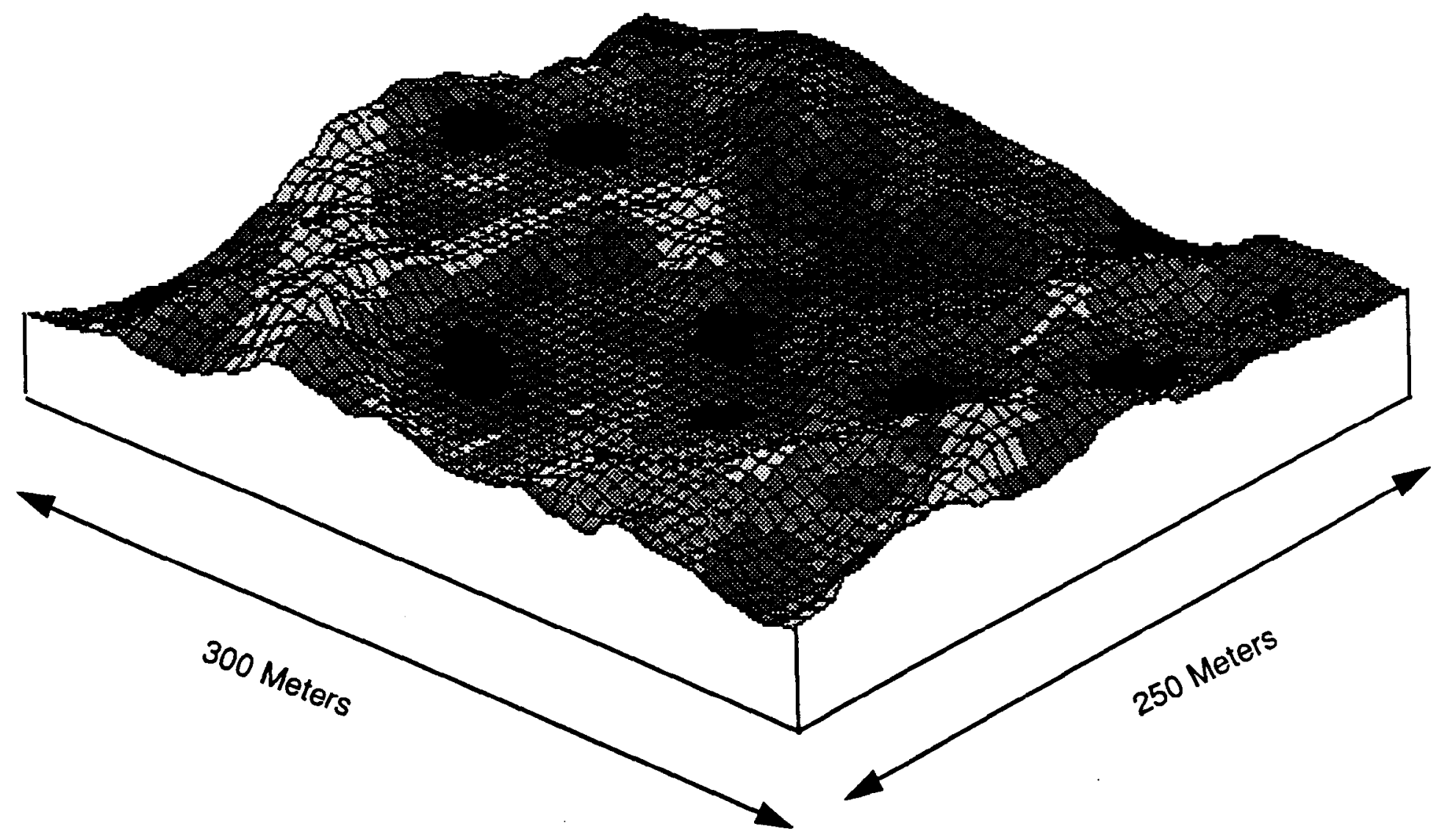

Vertical Exaggeration 12X

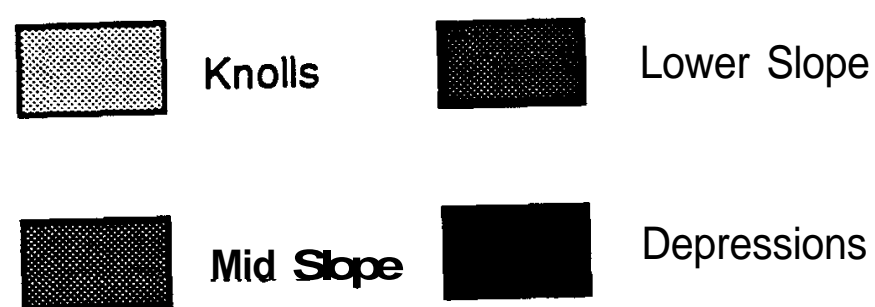

(Figure 4) Management Units Draped on the Digital Elevation Model 